\title{
LETTERS
}

\section{An ethical perspective on the use of secure care for youth with severe substance use}

As clinical ethicists, we read with interest the recent CMAJ commentary by Pilarinos and colleagues. ${ }^{1}$ In British Columbia, discussion is ongoing regarding secure care legislation for youth involved in high-risk substance use, ${ }^{2}$ and we commend these authors for bringing forward their concerns. We encourage application of an ethical lens, incorporating ethical principles and consideration of a range of ethical issues, in development of policy and treatment programs for this population.

Before consideration of an intervention contrary to an individual's wishes, a substantial risk of harm must be established. Harms of high-risk substance use by youth can range from decreased performance at school to death by overdose. ${ }^{3}$ Longerterm, yet less clearly documented effects, such as impacts on the developing brain, are also of serious concern.,4

Overriding autonomy by means of involuntary treatment should never be taken lightly, because this can cause substantial harms. Many youth possess the capacity and legal authority to make decisions regarding health care. ${ }^{5,6}$ However, some scholars posit that individuals with severe substance use disorders may struggle to follow through on decisions to reduce or abstain from substance use owing to the neurobiologic effects of addiction, leading to actions that go against their authentic values or best interests. $^{7}$ The question of whether an individual with a severe substance use disorder can be capable of making autonomous decisions with respect to their substance use and treatment has not been settled. Decision-makers must therefore balance the potentially coercive effects of addiction against the authoritative act of involuntary treatment.

Given the risk of substantial harm and potentially compromised capacity related to high-risk substance use, intervening against a youth's wishes to compel treatment could be ethically justifiable in some cases. However, ethical justification for such intervention must meet the following criteria. ${ }^{8,9}$

First, intervention is effective (beneficence). Although intervening to "do something" may be tempting, the intervention must have documented efficacy to be justifiable. Pilarinos and colleagues acknowledge that "addiction treatment programs are effective for some," ${ }^{1}$ but before secure care is considered, the nature and goal of the intervention, as well as individuals for whom it is likely to be effective, must be identified. If evidence does not support effectiveness of secure care in meeting treatment goals, such infringement on youth autonomy is ethically problematic. Given the paucity of evidence, research into such interventions may be acceptable, providing it is methodologically sound, as well as scientifically and ethically justified.

Second, intervention is the least intrusive yet effective option (autonomy). As well as being effective, an intervention should be the least intrusive. The intervention must be proportional to possible harms and benefits. Desperate situations may justify substantial intrusions on freedoms, while less serious situations do not. It would be ethically problematic to design a system in which youth were routinely involuntarily placed in secure care when less restrictive approaches would likely be effective. Therefore, it is important to provide a continuum of care to ensure access to the least intrusive services.

Third, intervention does not cause greater harm than it seeks to prevent (nonmaleficence). Mandating secure treatment may be ethically justifiable given the duty to protect youth from harm; for example, when a youth has overdosed multiple times over a short period and is likely to experience severe harms or die. However, this duty is not licence for involuntary treatment for all youth who use substances. A range of potential harms related to secure care must be considered, including risks in overriding autonomy (e.g., distrust in providers and "the system"), destabilizing effects and increased risk of overdose after treatment. ${ }^{1}$ It is critical to assess on an individual basis whether risks of treatment are outweighed by benefits, such as detoxification, assessment and stabilization (including improvement of decisional capacity). ${ }^{10}$ Appraising risks and benefits associated with substance use from the youth's perspective is necessary to understand why they are using (e.g., to cope with trauma) and the alternatives available to them. ${ }^{3}$

Fourth, intervention is nondiscriminatory (justice). Secure care for some youth must not hold them to a higher standard than others who are similarly situated. There must be clear criteria for those who would be treated involuntarily in secure care, such that like cases are treated alike.

Fifth, intervention is fair (justice). Highrisk substance use may be linked to social determinants of health that have been inadequately addressed through current systems (e.g., poverty, racism). It is important to address the root causes of substance use, and provide culturally safer care, particularly for underserved communities (e.g., Indigenous youth). This discussion must be placed in a larger social context, as the intersections with systemic inequities and injustices are numerous.

Justice also requires that we address issues of resource allocation and procedural justice. We must leverage current resources to target gaps to create an accessible system of care for all youth with challenges related to substance use. Similarly, if secure care is implemented, procedural justice requires appropriate stakeholder engagement (including youth, parents and communities affected by substance use) and robust safeguards to protect the rights of youth in secure care (e.g., fair appeal process).

Finally, the state has a special duty to care for and protect minor youth. For youth with severe substance use disorders, decisional capacity regarding substance use may be compromised or absent. Involuntary treatment for this population may be justifiable if the demonstrated benefits outweigh the potential 
harms and if issues of autonomy and justice are fully taken into account.

Numerous ethical issues arise when developing policy and treatment programs for the subgroup of youth with high-risk substance use, and we strongly support including ethicists in these discussions. Approaches such as secure care have potential to cause harm, but that reality cannot lead to inaction. Instead, evidence, risks and benefits must be comprehensively evaluated, with thorough consideration of youth autonomy, cultural safety, fair process, resource allocation and stakeholder consultation. Swift action and adequate funding are needed to ensure youth with high-risk substance use have access to the most effective and least restrictive services that can meet their needs.

\section{Beth A. Clark PhD}

Postdoctoral fellow, University of British Columbia, Vancouver, BC
Nina Preto MSc (Bioethics) PhD

Ethicist, Clinical Ethics Service, Provincial

Health Services Authority of British

Columbia, Vancouver, BC

\section{Bethan Everett MBA PhD}

Ethicist, Vancouver Coastal Health,

Vancouver, BC

Jenny M. Young MSW MA (Bioethics)

Director Ethics Services, Providence

Health Care, Vancouver, BC

Alice Virani MPH PhD

Director, Clinical Ethics Service, Provincial Health Services Authority of British

Columbia, Vancouver, BC

Cite as: CMAJ 2019 February 19;191: E195-6. doi: 10.1503/cmaj.71504

\section{References}

1. Pilarinos $A$, Kendall $P$, Fast $D$, et al. Secure care: more harm than good. CMAJ 2018;190:E1219-20.

2. Hogg G. Bill M 240 - 2017: Safe Care Act, 2017. 2017 Legislative session. 40th Parliament, 6th sess., 2017. Available: www.leg.bc.ca/parliamentary-business/ legislation-debates-proceedings/40th-parliament/ 6th-session/bills/first-reading/m240-1 (accessed 2018 Nov. 6).

3. Turpel-Lafond ME. A review of youth substance use services in B.C. Victoria: Representative for Children and Youth; May 2016. Available: https://rcybc.ca/ substanceuse (accessed 2018 Nov. 6).

4. Volkow ND, Koob GF, Croyle RT, et al. The conception of the ABCD study: from substance use to a broad NIH collaboration. Dev Cogn Neurosci 2018;32:4-7.

5. Infants Act [RSBC 1996] Chapter 223; Updated 2018 Nov. 7

6. Coughlin KW; Canadian Paediatric Society. Medical decision-making in paediatrics: infancy to adolescence. Paediatr Child Health 2018;23:138-46. doi: 10.1093/pch/pxx127.

7. Volkow ND, Koob GF, McLellan AT. Neurobiologic advances from the brain disease model of addiction. N Engl J Med 2016;374:363-71.

8. Browne A, Blake M, Donnelly M, et al. On liberty for the old. Can J Aging 2002;21:283-93.

9. Young JM, Everett B. When patients choose to live at risk: What is an ethical approach to intervention? BCMJ 2018;60:314-8.

10. Charles G. Secure care summary report (Part One): secure care legislation [technical report]. Victoria: Queen's Printer; 2000. doi: 10.13140/ RG.2.2.17514.52164.

Competing interests: None declared. 